\title{
O ESTADO DE NATUREZA VIRTUAL E A JUSTIFICAÇÁO DAS LIBERDADES IRRESTRITAS NAS REDES SOCIAIS
}

\author{
S THE VIRTUAL STATE OF NATURE AND THE JUSTIFICATION OF \\ UNRESTRICTED FREEDOMS IN SOCIAL NETWORKS
}

\author{
Roberto Senise Lisboa (In Memoriam) $)^{\mathrm{I}}$ \\ André Faustino ${ }^{\mathrm{II}}$
}

I Pontifícia Universidade Católica de São Paulo, São Paulo, SP, Brasil. Doutor em Direito

\footnotetext{
II Faculdades Metropolitanas Unidas, São Paulo, SP, Brasil. Mestre em Direito da Sociedade da Informação E-mail: faustinoadv01@gmail.com
}

Resumo: A popularização do uso da internet trouxe grandes desafios para o Direito, como a proteção da privacidade e a regulação do negócio eletrônico; e, principalmente a regulação das relaçóes humanas nas redes sociais. Como o ambiente virtual é por essência difuso e de difícil controle, as pessoas, ao se utilizarem desse "espaço", agem muitas vezes de modo diferente do "mundo físico", pela falsa sensação de que o ambiente virtual permite tudo. Contam com o possível anonimato e a falta de empatia. Assim, as normas de convivência social são muitas vezes ignoradas, prevalecendo o interesse individual, o que se assemelha ao conceito do estado de natureza. $\mathrm{O}$ objetivo deste artigo é estabelecer a relação entre o conceito do estado de natureza de Thomas Hobbes com o surgimento do estado de natureza virtual, justificandose ou não, na internet, um ambiente de liberdades irrestritas.

Palavras-chave: Sociedade da informação; Redes sociais; Estado de natureza virtual; Liberdade de expressão

\begin{abstract}
The popularization of the use and access of the internet has brought great challenges to the Law, such as the protection of privacy and the regulation of electronic contracts; and especially the regulation of human relations on social networks. As the virtual environment is by nature diffuse and difficult to control, when people use this "space", they often act differently from the "physical world", due to the false feeling that the virtual environment allows everything. They have possible anonymity and a lack of empathy. Thus, the norms of social coexistence are often ignored, with individual interest prevailing, which is similar to the concept of the state of nature. The purpose of this article is to establish the relationship between the concept of Thomas Hobbes' state of nature, whether or not, an environment of unrestricted freedom is justified.
\end{abstract}

Keywords: Information society; Social medias; Virtual state of nature; Freedom of expression. 


\section{Introdução}

Toda pessoa, enquanto indivíduo, tem a necessidade de ser livre e essa liberdade se apresenta como forma de justificar a sua existência, quer seja pela incapacidade de compreensão do mundo que a rodeia e, daí se projetar através das suas expressóes da alma como, por exemplo, a música ou a poesia, quer seja por um desejo de evidenciar as suas carências e, dessa forma, reunindo-se em sociedade. O ser humano, enfim, é um ser político por natureza ${ }^{1}$.

Ao longo da passagem do tempo, o ser humano, através da sua capacidade de modificar o ambiente onde vive, desenvolveu inúmeras formas de potencializar essa capacidade de expressão ou exteriorização de uma necessidade de liberdade, de uma necessidade de "ser" no mundo que o cerca.

As criaçóes tecnológicas ganharam incremento, possibilitando a expressão dessa liberdade como, por exemplo: a criação da imprensa, do rádio, da televisão ou da internet, ou seja, houve um desenvolvimento de meios de comunicação voltados para um maior exercício dessa liberdade, principalmente a de expressão ou de informação.

Entretanto, no momento inicial dessas criações não existia a democratização do acesso a esses meios de comunicação sob o ponto de vista da criação e, também, do "consumo" desses conteúdos; existindo uma lacuna que serviu para o desenvolvimento de tecnologias que permitissem ao indivíduo o acesso a esses meios de comunicação e, muito mais, a criação de conteúdos, assim possibilitando a expressão da sua liberdade através de uma liberdade de expressão.

A popularização do acesso e uso da internet na década de 1990 trouxe, justamente, essa possibilidade, a de oferecer um ambiente onde o indivíduo pudesse exercer a sua liberdade de forma irrestrita, sem regulação, sem responsabilização, já que era um espaço virtual, era um mundo diferente do mundo real vivido, cruel, irregular.

Esse novo ambiente que surgia de forma popular, no final do século $\mathrm{XX}$, mudou a forma de se estabelecer as relaçóes sociais, alterando significativamente a forma como o ser humano passou a se relacionar, fazendo desaparecer a necessidade do contato físico, colocando em xeque algumas construçôes sociais desenvolvidas ao longo da história humana, como a empatia, por exemplo, e por mais contraditório que pareça, a internet e as redes sociais, se tornaram o ambiente de exposição e de estabelecimento de relaçôes sociais, com a vantagem da proteção de um possível anonimato.

Esse anonimato e essa relação humana distante fisicamente e difusa, sob o ponto de vista da impossibilidade de definição de uma identidade real, criou nas redes sociais o ambiente perfeito para os indivíduos se relacionarem, produzirem conteúdo, exporem a sua intimidade ou violarem direitos de forma sistemática e em todas essas possibilidades existe um ponto em comum, a falsa sensaçáo de um ambiente de liberdades irrestritas, protegidas pela dificuldade da identificação real dos indivíduos, por conta dos aspectos de infraestrutura e tecnologia relacionados com a internet e pela confusão entre mundo real e mundo virtual.

1 ARISTÓTELES "Ética a Nicômaco". Tradução de Leonel Valandro e Gerd Bornheim. São Paulo: Abril Cultural, 1973. Vol. IV: Os Pensadores. 
Diante dessa dicotomia, entre real e virtual, o indivíduo no interior das redes sociais possui a crença de que dentro desse ambiente é possível o exercício das suas liberdades de forma irrestrita, daí evidenciando o surgimento de forma endêmica de conteúdos relacionados aos discursos de ódio, fake news, grupos que fazem apologia ao nazismo, dentre outros conteúdos.

Essa postura de liberdades irrestritas dentro do ambiente virtual muito se assemelha com a ideia do estado de natureza proposto por Hobbes ao justificar a necessidade de um contrato social, já que o indivíduo no estado de natureza teria, justamente, liberdades irrestritas, surgindo a possibilidade de eliminação, inclusive, dos seus semelhantes como forma de satisfazer os seus desejos imediatos dentro desse ambiente, as redes sociais são o local de individualismo exacerbado.

As redes sociais criam essa falsa sensação nos indivíduos e a dificuldade de regulação da internet facilita mais esse tipo de comportamento, sendo o local existente que bem se assemelha ao estado de natureza hobbesiano, dessa forma justificando, mesmo que de forma inconsciente, o aparecimento de um estado de natureza virtual, que surgirá diante da impossibilidade de regulação por parte do Estado, inexistindo um contrato social que limite essas liberdades irrestritas dentro do ambiente das redes sociais e da internet.

Por fim, o propósito deste trabalho é buscar evidenciar a relação entre uma ideia do estado de natureza virtual, partindo do conceito de estado de natureza de Hobbes, relacionado com a falsa sensação dos indivíduos dentro das redes sociais, de um ambiente de liberdades irrestritas.

A pesquisa foi realizada com enfoque jurídico-sociológico, realizando a revisão da bibliografia apontada nas referências, procurando visitar a doutrina, a legislação e o que foi produzido sobre o tema apresentado. A leitura das obras apontadas nas referências foi a base do presente trabalho, em que a interpretação desses textos serviu de subsídio para a construção do que será apresentado.

\section{As redes sociais e as liberdades irrestritas}

As redes sociais assumiram o papel da praça pública, se tornaram o local de "encontro" e discussão sobre os fatos da vida e, mais ainda, o lugar onde é possível expor a vida, a intimidade, as vitórias ou, até mesmo, desenvolver uma nova identidade que, inclusive, não guarde relação com a identidade real das pessoas, é onde existe a possibilidade de se criar um novo "eu" descolado da própria realidade.

Essa possibilidade da derivação da ideia de identidade dentro do ciberespaço irá facilitar a falsa sensação de que dentro desse espaço as liberdades são irrestritas, esse "eu" virtual pode tudo, quer seja por expressar, através dessa nova identidade, aquilo que é impossível no "mundo real" por existirem limitações morais, legais e sociais, quer seja porque nesse "mundo virtual" o anonimato e a dificuldade de responsabilização estimularem comportamentos livres de qualquer repressão estatal ou moral.

Barbosa $^{2}$ bem evidencia essa questão da crise na identidade que ocorre no ciberespaço:

2 BARBOSA, Marco Antônio. Pós-modernidade: a identidade real ou virtual? Revista Direitos Culturais, Santo Ângelo, v.5, n.8, p. 78-79. Jan/jun.2010. 
As identidades pessoais foram abaladas por essas transformaçóes e a ideia que se tinha da identidade subjetiva enquanto sujeitos plenamente integrados ficou assim comprometida. Esse duplo movimento (deslocamento e descentração) dos indivíduos, tanto do seu lugar no mundo social e cultural quanto de si mesmos, é identificado como a constituição de uma crise de identidade para o indivíduo e para a noção de identidade cultural. Esse sujeito, previamente vivido ou pensado como tendo uma identidade unificada e estável, vai se fragmentando. Ele não é mais concebido como sendo composto de uma só e única identidade, mas de várias, algumas vezes entre si contraditórias ou não resolvidas.

Assim, as relaçóes estabelecidas dentro das redes sociais serão dotadas de grande efemeridade, já que dentro dessa comunidade criada em torno de cada indivíduo será permitido total controle desse mundo individual, onde cada dono de perfil será soberano dentro da sua comunidade criada e cada dono de perfil irá se relacionar com outros donos de perfil, estabelecendo verdadeiros mundos paralelos no ambiente virtual.

As regras legais estabelecidas por um ordenamento jurídico, o direito posto, em muito não produzirá reais efeitos como forma de controle dessas relaçóes estabelecidas no interior do ciberespaço, já que o indivíduo no mundo virtual buscará alijar-se de qualquer grilhão que o prenda de qualquer forma de controle, o ambiente virtual, a internet, as redes sociais, serão o lugar da liberdade, da forma de expressão máxima das liberdades virtuais e isso irá legitimar uma falsa sensação de que dentro desse ambiente poderão existir liberdades irrestritas.

Umas das questôes, justamente, que irá facilitar esse tipo de sensação é a falta de percepção dos indivíduos, dentro do ciberespaço, de uma noção de consequência, já que a vida cibernética, a convivência dentro do mundo virtual será baseada em uma instantaneidade e em uma relaçáo diferenciada com o tempo. O tempo das redes sociais é o tempo da máquina, que rompe com a ideia do cronos, é o tempo imperfeito, da relação imediata, nada é feito para durar para sempre, mas para ser passageiro, temporário, efêmero e, dessa forma, a noção de consequência dos atos praticados dentro do ciberespaço encontra um legitimador relacionado com a desnecessidade do pensamento posterior, a ação imediata facilita a desconexão com a noção de consequência.

Portanto os resultados são imediatos, a satisfação é imediata e as relações são imediatas, o mundo virtual facilita a ideia de desnecessidade da continuidade das relaçóes, a ideia de inexistência de resultados em uma conduta, noçóes fundamentais para compreensão dos dogmas estabelecidos pelo Direito. Essa forma de pensar irá facilitar a ideia de liberdades irrestritas, já que o que possuirá valia será o agir e não o pensar - agir - pensar, dessa forma o indivíduo nas redes sociais será movido pelo impulso, que será direcionado para satisfaçáo das necessidades imediatas individuais, onde cada usuário procurará satisfazer-se de forma plena, pouco importando o outro ou qualquer forma de controle.

Logo no início dessa popularização da internet começaram a surgir pensamentos que justificaram essa aura libertária da rede mundial de computadores, desenvolveu-se uma noção de ciberespaço $^{3}$ ou de um mundo virtual e, com isso, o fortalecimento de um mundo onde tudo era possível, um lugar de liberdades irrestritas.

Em 1996, John Perry Barlow publicou um documento intitulado "A declaração de independência do Ciberespaço" onde deixa clara essa sensação da existência de "dois mundos" um real e um virtual. Esse documento foi uma reação à publicação de uma lei norte americana, o

3 LÉVY, Pierre. Cibercultura. São Paulo: Editora 34. 1999. 
Communication Decency Act, que tinha como objetivo tratar a questáo da pornografia na internet, ou seja, era uma forma de regulaçáo desse ambiente, o que contrariava o senso coletivo de que a internet era um lugar isento de regulação.

Barlow deixa evidente essa noção de que a internet era o local de liberdade, imune às regulaçóes externas por parte do Estado, um mundo a parte e, de certa forma, esse tipo de pensamento exprime a falsa noção de que a internet não possui regulação, conforme vemos a seguir:

Estamos formando nosso próprio Contrato Social. Essa maneira de governar surgirá de acordo com as condiçôes do nosso mundo, não do seu. Nosso mundo é diferente. $\mathrm{O}$ espaço cibernético consiste em ideias, transaçôes e relacionamentos próprios, tabelados como uma onda parada na rede das nossas comunicaçóes. Nosso é um mundo que está ao mesmo tempo em todos os lugares e em nenhum lugar, mas não é onde pessoas vivem. Estamos criando um mundo que todos poderão entrar sem privilégios ou preconceitos de acordo com a raça, poder econômico, força militar ou lugar de nascimento. Estamos criando um mundo onde qualquer um em qualquer lugar poderá expressar suas opiniōes, não importando quão singular, sem temer que seja coagido ao silêncio ou conformidade. Seus conceitos legais sobre propriedade, expressão, identidade, movimento e contexto não se aplicam a nós. Eles são baseados na matéria ${ }^{4}$.

Essa falsa sensação de que o ciberespaço representa um "lugar" onde não existe o alcance do Estado, onde cada indivíduo poderá exercer a sua liberdade de forma irrestrita, sobrepondo o interesse individual sobre outro interesse individual, irá se aproximar do conceito hobbesiano de estado de natureza.

Alguns fenômenos ocorridos e potencializados pela democratização do acesso e uso da internet evidenciam essa similaridade com o homem do estado de natureza hobbesiano como, por exemplo, a propagaçáo de discursos de ódios ou a disseminação de desinformação através fake news e, embora, os indivíduos possam ser considerados iguais quando inseridos no ciberespaço, assim como os indivíduos são iguais no estado de natureza, essa igualdade não impede que um queira se sobrepor ao outro, pois assim como no "mundo real" do conceito de Hobbes, a busca será por poder, que na redes sociais pode ser traduzido em seguidores, likes, compartilhamentos, etc.

Para Hobbes, a busca dos indivíduos, dentro do estado de natureza, será guiada em torno de uma completude de seus sentidos e da própria imaginaçáo, esse caminho percorrido será voltado para satisfazer as necessidades individuais e justificará qualquer tipo de conduta em prol dessa satisfação. $\mathrm{O}$ resultado disso serão indivíduos mais poderosos sob o ponto de vista da sua plenitude interior egoísta, mas em um segundo momento será, também, um indivíduo que devido seu poder, subjugou os outros.

Esse ponto é bem evidenciado por Hobbes em O Leviatã:

E ao homem é impossível viver quando seus desejos chegam ao fim, tal como quando seus sentidos e imaginação ficam paralisados. A felicidade é um contínuo progresso do desejo, de um objeto para outro, não sendo a obtenção do primeiro outra coisa senão o caminho para conseguir o segundo (...) Assinalo, assim, em primeiro lugar, como

4 BARLOW, John Perry. Disponível em: <http://www.dhnet.org.br/ciber/textos/barlow.htm>. Acesso em: 02 fev. 2020. 
tendência geral de todos os homens, um perpétuo e irrequieto desejo de poder e mais poder, que cessa apenas com a morte 5

Essa vida no estado de natureza hobbesiano será a própria guerra eterna do indivíduo nesse estado, pois a inquietação será constante, já que cada um desejará mais liberdades e consequente domínio sobre os outros indivíduos, é uma jornada incansável atrás de poder e mais liberdade, um círculo vicioso de consumo da vida, que só irá se encerrar através da morte, mas essa busca incessante por mais e mais liberdade, por mais e mais controle sobre o outro, irá se assemelhar ao comportamento dos indivíduos dentro do ciberespaço, que buscam liberdades irrestritas para satisfazerem seus desejos. Hobbes, ainda, trata dessa questão em O Leviatã:

O fim último, causa final e desígnio dos homens (que amam naturalmente a liberdade e o domínio sobre os outros), ao introduzir aquela restriçấo sobre si mesmos sob a qual os vemos viver nos Estados, é cuidado com sua própria conservação e com uma vida mais satisfeita. Quer dizer, o desejo de sair daquela mísera condição de guerra que é a consequência necessária das paixốes naturais dos homens, quando não há um poder visível capaz de os manter em respeito, forçando-os, por medo do castigo, ao cumprimento de seus pactos e ao respeito àquelas leis de natureza que foram expostas nos capítulos décimo quarto e décimo quinto ${ }^{6}$.

Dessa forma, as redes sociais e a sua dinâmica de funcionamento harmonizam perfeitamente com uma possibilidade do exercício de liberdades irrestritas, já que facilitam o anonimato e são um ambiente difuso. A arquitetura da internet facilita que cada usuário possa criar um perfil que náo corresponda com a sua identidade real, facilitando o surgimento de um pensamento que possa legitimar um ambiente que estimule o exercício de liberdades irrestritas e que propicie o desenvolvimento de uma ideia de satisfaçáo plena e imediata das necessidades existenciais do indivíduo que utiliza essas redes, aproximando-se do homem no estado de natureza.

\section{Violência positiva: exposição como forma de anular o outro}

A exposição será uma das formas de violência através das redes sociais. A busca por likes, por compartilhamentos e por protagonismo irá possibilitar o surgimento de um comportamento que buscará a satisfação de prazeres imediatos e uma anulação do outro.

Isso irá evidenciar a possibilidade de que dentro do ciberespaço a liberdade é irrestrita, no sentido de que a exposição servirá para que a vida, a existência daquele que posta o conteúdo dentro da sua rede social buscará anular ou competir com os outros indivíduos contidos em sua mesma rede, basta um clique para eliminar qualquer obstáculo, qualquer possível ameaça que possa existir a essa exposição da vida, essa criação de uma vida falsa.

As redes sociais são, essencialmente, o espaço para a mentira, existem para que cada um projete nelas os seus desejos e anseios que não podem ser realizados no mundo real, existe um excesso de positividade, de perfeição e, justamente, essa perfeição e positividade é que representarão uma das formas de legitimar a anulaçáo do outro através de condutas vedadas

5 HOBBES, Thomas. Leviatá, ou Matéria, Forma e Poder de um Estado Eclesiástico e Civil. Col. Os Pensadores. São Paulo: Ed. Abril Cultural, 1979, p. 60.

6 Idem, p. 103. 
pelo ordenamento jurídico como, por exemplo a propagação de discursos de ódio ou através de condutas que afrontam uma ideia de moral social como, por exemplo, criar uma "vida virtual" que não corresponde a vida real.

Essa positividade em demasia procurará anular o outro. A vida positiva, vivida dentro das redes sociais e dentro de um mundo virtual, buscará ser completada pela necessidade do desempenho, da quantificação, que é expressada através da contagem de likes, de visualizaçóes de publicaçóes, da quantidade de seguidores e assim sempre se relacionando com uma ideia de desempenho, de máxima potência em viver essa vida plena, que será alimentada pelo desejo alheio em consumir essa vida exposta.

Assim é construída uma base que permitirá o desenvolvimento de um comportamento social e um perfil, dentro das mídias sociais, que será desconectado da ideia de realidade e essa positividade servirá como uma forma de anular o outro.

Chul $\mathrm{Han}^{7}$ desenvolve a ideia de violência positiva e como ela pode se manifestar dentro de uma sociedade marcada pelo desempenho e pelo cansaço:

A sociedade de hoje se desonera cada vez mais da negatividade do outro e do que é alheio. É justamente o processo de globalização que acelera a suspensão das barreiras e diferenciação. Mas a desconstrução da negatividade não pode ser equiparada ao desaparecimento da violência, pois ao lado da positividade, que é exercida sem qualquer inimizade ou predomínio. Poder não é apenas o excesso de negatividade, mas também o excesso de positividade, a desmedida do positivo se expressa como superdesempenho, superprodução e supercomunicação, como um hiperchamar a atenção e hiperatividade. Ocasionalmente, a violência da positividade é mais fatal do que a violência da negatividade.

E o caráter difuso, de uma falsa ideia de democracia digital das redes sociais, onde todos podem expor suas vidas, criando essas mesmas novas vidas, facilitará o surgimento de um comportamento de anulaçáo do outro. O egoísmo do indivíduo na rede social irá se assemelhar ao egoísmo do indivíduo do estado de natureza hobbesiano. A vaidade e a possibilidade de atingir um número infinito de pessoas através de uma postagem, estimulará a corrida pela exposição da vida como forma de ganhar protagonismo e constituir uma espécie de capital de pessoas, onde cada curtida, cada compartilhamento, representará patrimônio virtual de grande valia.

A exposição nas redes sociais será uma forma de dar sentido ao vazio da vida de verdade, da vida imperfeita, mas real. Será uma justificativa à própria existência e a liberdade que essa vida virtual propicia será sedutora. Assim os usuários das redes sociais poderão criar seu próprio mundo, que buscará se tornar uma forma de opor a sua vida de forma efetiva em relação aos outros. A satisfação dos desejos e das vontades imediatas e individuais justificarão a necessidade da existência de liberdades irrestritas, dessa forma justificando a criação de uma vida de mentira, de conteúdos de mentira, de possibilidades de agressóes a outros, de compartilhamento de conteúdos impróprios, de possibilidade de ofensas a direitos de outros, como forma de justificar essa existência ficta dentro das redes sociais.

Por mais verdadeiro que um perfil em uma rede social possa parecer e o seu dono possa ser real, o conteúdo postado nesse perfil pode representar uma vida que não corresponde a verdade e a única finalidade é expor isso como forma de agressão, mesmo que inconscientemente,

7 HAN, Byung-Chul. Topologia da violência. Petrópolis: Vozes, 2017, pp. 9-10. 
aos outros usuários da mesma rede. A exposição irá servir para mostrar como a vida ali exposta merece ser desejada e esse desejo dos outros por essa vida exposta é que irá motivar cada vez mais a exposição, cada vez mais liberdade, cada vez mais necessidade de expressão.

A felicidade exposta, a perfeição apresentada irá ser artificial, será uma construção que buscará seduzir o outro para que ele consuma a vida exposta, será uma roda perversa que gira para o lado daquele que mais expóe, que mais influência, que mais patrimônio humano possua. Cada seguidor, cada curtida representará um bem para o dono daquela rede social, dessa forma permitindo que mesmo que falsa, aquela vida irá se apresentar como verdadeira dentro do ciberespaço.

Lanier $^{8}$ irá explicar como essa criação de uma vida falsa acontece dentro das redes sociais:

Esse componente está quase sempre presente, embora normalmente não fizesse parte do projeto inicial de uma máquina Bummer. Embora o número de perfis falsos seja desconhecido, eles alcançam uma escala enorme e tomam conta do ambiente. Bots, inteligências artificiais, agentes, comentaristas falsos, amigos falsos, seguidores falsos, cartazes falsos, perfis falsos: é uma miscelânea de fantasmas.

E toda essa busca do indivíduo pós-moderno pela sua liberdade irá se relacionar com uma sociedade que busca a exposição ou espetáculo nas redes sociais, onde cada um será Narciso, mas ao invés de buscar o reflexo na água, os indivíduos possuirão uma coletividade indefinida de possíveis seguidores para refletir a sua imagem, o espelho deu lugar ao smartphone e, na sociedade hiper-técnica, extremamente inserida em um mundo de aparências e pautada pela necessidade de performance ou resultado, a possibilidade de liberdade irrestrita será a porta de passagem para o espetáculo?.

A necessidade de tornar pública a intimidade, a vida privada na sua totalidade, é uma forma de alimentar o funcionamento da "roda da vida virtual", já que com o individualismo exacerbado, fruto da noção de estado de natureza virtual, a aparência será fundamental para que os holofotes se voltem para aqueles que mais protagonismo possuírem na rede.

Termos antes inimagináveis surgem em decorrência dessa exposição como, por exemplo, digital influencers, que nada mais são que aqueles que, na "estrada" da busca do espetáculo, simplesmente venceram, chegaram até o fim, conheceram o que vem depois da "luz no fim do túnel". Sua existência, mesmo que vazia, influencia a existência de outros. Vivemos o tempo dos gurus, dos coachs, o indivíduo necessita de mentores, já que ele sozinho não consegue mais suportar as suas próprias deficiências, sua própria existência ou limitaçôes enquanto ser humano, precisando encontrar no guia, no influenciador, o sentido da sua vida, através da vida exposta por aquele que influencia, mesmo que ele, também, possua uma vida vazia.

Se Deus é o alfa e o ômega, hoje em dia o Deus Robô é o Instagram e o Twitter, ou seja, no interior dessas plataformas é possível alcançar a graça, a redenção e esse descolamento

8 LANIER, Jaron. Dez argumentos para você deletar agora suas redes sociais. Rio de Janeiro: Intrinseca, 2018, p. 53.

9 Cf. Debord: "A vedete do espetáculo, a representação espetacular do homem vivo, ao concetrar em si a imagem possível, concentra, pois, essa banalidade. A condição de vedete é a especialização do vivido aparente, o objeto de identificação com a vida aparente sem profundidade, que deve compensar o estilhaçamento das especializaçóes produtivas de fato vividas. As vedetes existem para representar tipos variados de estilos de vida e de estilos de compreensão da sociedade, livres para agir globalmente”. DEBORD, Guy. A sociedade do espetáculo. Rio de Janeiro: Contraponto, 2017, p. 64. 
permite a existência dessa dualidade fática que permeia o pensamento coletivo pós-moderno, evidenciado na ideia "mundo real" um ser humano, "mundo virtual" outro ser humano. E tudo isso é possível por conta dessa necessidade de dar publicidade à vida pessoal, pois ao publicizar a intimidade, o indivíduo mostra para todos a sua existência, que no estado de natureza virtual, representará a ação de sobrepor seus desejos pessoais em detrimento dos desejos pessoais do outro, e, conforme Hobbes, esse homem passa a ser o lobo do homem.

Essa extensão da possibilidade de publicidade da vida é bem explicada por Hannah Arendt em seu livro A Condição Humana, ao expor o reflexo, justamente, dessa exposição:

O termo público denota dois fenômenos intimamente correlatos, mas não perfeitamente idênticos. Significa, em primeiro lugar, que tudo que vem a público pode ser visto e ouvido por todos e tem a maior divulgação possível. Para nós, a aparência - aquilo que é visto e ouvido pelos outros e por nós mesmos - constitui a realidade. Em comparação com a realidade que decorre do fato de que algo é visto e escutado, até mesmo as maiores forças da vida íntima - as paixóes do coração, os pensamentos da mente, os deleites dos sentidos - vivem uma espécie de existência incerta e obscura, a não ser que, e até que, sejam transformadas, desprivatizadas e desindividualizadas, por assim dizer, de modo a se tornarem adequadas à aparição pública ${ }^{10}$.

Através de uma dinâmica agressiva, o desenvolvimento das redes sociais irá permitir a criação de vínculos efêmeros de relacionamento social, mas com um interesse em comum, a troca de um capital virtual existente nessas redes, quem tem mais, expóe mais, quem tem menos, busca expor mais, essa será a lógica da exposição e a liberdade de expressão servirá de legitimação da possibilidade dessa exposição.

No interior dessas redes sociais o indivíduo passa a perder a capacidade de respeito à individualidade do outro, no mundo onde a técnica rompe com a alma, com a poesia, cada vez mais a empatia desaparece. $O$ robô é o paradigma, a inteligência artificial é infalível se comparada com a inteligência humana, criador sucumbe à criatura, a máquina não sente, não tem uma complexidade psíquica e fisiológica, apenas executa o comando, possuindo a frieza que lhe é peculiar, pois é uma criação exclusiva da técnica, e, dessa forma, esse "sentimento" de potência, de performance, é transmitido para os indivíduos, que nas redes sociais, passarão a ser verdadeiras máquinas em busca do êxito na exposição, na satisfação de seus desejos pessoais.

E esse descompromisso com o próximo, e aqui no próprio sentido cristão efetivamente, aguda o processo de necessidade de uma vida em estado de natureza, em que se faz necessária a manutenção de uma torpeza profunda que eliminará qualquer obstáculo em busca da satisfação dos desejos individuais, a liberdade irrestrita é a forma de garantia da plenitude individual e da desnecessidade de olhar face a face o próximo, de sentir o sentimento do próximo, facilita, cada vez mais, a eliminação da porção humana que possuímos.

Dessa forma, a falta de contato físico, do "olhar nos olhos" fica bastante diminuída a medida em que as relaçóes pessoais no "mundo real" vão se esvaziando, pois o chat, a timeline, representam a figura da praça, da rua, que outrora eram o ponto de encontro, de reunião das pessoas, e essa falta do contato face a face possuirá reflexos no campo da moral, pois a sua eliminação representará uma oportunidade para, cada vez mais, as relaçóes se tornarem artificiais,

10 ARENDT, Hannah. A condição humana; trad. Roberto Raposo, 10a. ed. Rio de Janeiro: Forense Universitária, 2005, p. 59. 
efêmeras e automáticas, o homem no estado de natureza virtual é o eu-robô, com a inversão das regras ${ }^{11}$ que representam o seu imperativo categórico, segundo Asimov.

Anthony Giddens, em seu livro a constituição da sociedade, irá bem evidenciar a necessidade dos encontros face a face e da importância dessa ocorrência, inclusive sob o ponto de vista moral:

Os números de pessoas que podem participar diretamente de encontros face a face são inerentemente estritamente limitados, exceto aqueles tipos de situação em que um ou poucos indivíduos se dirigem a uma multidão ou a um público à sua frente. Mas tais circunstâncias, é claro, exigem que os que estáo na multidáo ou no público renunciem ao contínuo contato face a face entre si. A primazia da face como meio de expressão e comunicação tem implicações morais. ${ }^{12}$

Sempre ocorrerá a exposição ao máximo em busca de notoriedade e de cada vez mais liberdade, o ponto de partida será através das opiniôes pessoais, manifestaçôes individuais sobre qualquer assunto ou fenômeno ocorrido, poderá ser do "alfinete ao foguete", eliminando o que quer que seja em busca da liberdade em poder expor, náo importa o resultado, náo importa a reação do outro, elimina-se a empatia, elimina-se a solidariedade, elimina-se a humanidade, elimina-se o outro, mas a liberdade estará lá garantida, os desejos serão satisfeitos e, cada vez mais, o individuo entrará em seu estado de natureza virtual.

A opinião pessoal como reação a tudo que é público ou coletivo é bem evidenciada por Bordieu, que trata sobre a crítica social do julgamento:

Vê-se, de fato, que a reivindicação do direito à "opinião pessoal" e a desconfiança em relação a todas formas de delegação, sobretudo, na política, inscrevem-se logicamente no sistema das disposiçóes próprias a indivíduos, cujo passado e projeto baseiam-se na aposta da salvação individual, escorada nos "dons" e "méritos" pessoais, na ruptura das solidariedades enfadonhas, inclusive, na negação das obrigaçôes incomodas, na escolha de privilegiar sistematicamente - tanto no habitat quanto no trabalho, tanto no lazer quanto na atividade mental - o privado, o íntimo ("em sua casa”) contra o que é público, coletivo, comum, qualquer, emprestado ${ }^{13}$.

O homem pós-moderno é por necessidade pós-humano, a humanidade intrínseca de cada indivíduo dá lugar a uma necessidade de alcance da infalibilidade da máquina. O ciborque não se abala, não sente medo, não sente fome, é um organismo mecânico - humano que supre todas as falhas e imperfeiçóes humanas e o indivíduo nas redes sociais busca, justamente essa perfeição, que tem o lado cruel que é o da eliminação da empatia, a máquina não é empática, não possui a necessidade de compreender o próximo. O homem pós-humano é o ser perfeito para existir no estado de natureza virtual.

$\mathrm{Na}$ pós-humanidade, a violência positiva de exposição como maneira de anular o outro é realizada mediante uma falsa percepção do que se entende por liberdade. No afã de alcançar

11 Cf. Asimov existem três lei base da robótica, que são: 1. Um robô não pode ferir um ser humano ou, por inação, permitir que um ser humano venha a ser ferido. 2. Um robô deve obedecer às ordens dadas por seres humanos, exceto nos casos em que tais ordens entrem em conflito com a Primeira Lei. 3. Um robô deve proteger a própria existência, desde que tal proteçáo náo entre em conflito com a Primeira ou com a Segunda Lei. ASIMOV, Isaac. Eu, Robô. São Paulo: Aleph, 2015, p. 45.

12 GIDDENS, Anthony. A constituição da sociedade, trad. Álvaro Cabral, $3^{a}$. ed. São Paulo: Editora WMF Martins Fontes, 2009, p. 78.

13 BORDIEU, Pierre. A Distinção: crítica social do julgamento, 2a . ed. Porto Alegre: Zouk, 2017, p. 389. 
a perfeição aparente, o homem máquina deixa de lado os seus problemas reais e passa a ser o influencer na política, nas questóes socioeconômicas e culturais, como senhor da verdade absoluta que infirma e anula o outro.

É a entronização do homem-máquina, que tem a necessidade de ser melhor que o outro homem-máquina, assim como ter razão do que declara na rede. Para ele, a informação ser completa ou incompleta, falsa ou verdadeira, é secundário, desde que sua realidade de mundo prevaleça. $\mathrm{O}$ homem-máquina se sente à vontade para exercer o poder da comunicação sobre os mais variados temas: pode se inserir na sociedade-mundo, de Georges Simmel ou de Edgard Morin; assim como debater a economia-mundo, de Fernand Braudel ou de Immanuel Wallerstein; ou mesmo a cultura-mundo, de Gilles Lipovetsky. Sente-se habilitado para discutir tudo, embora pouco saiba. Pode ter acesso a uma ou algumas informaçôes, sem ter necessariamente o conhecimento. O que importa é prevalecer a sua imagem e a sua opinião. Essas são as suas duas maiores necessidades. Assim, sentirão que a liberdade existe realmente.

Para o homem-máquina, não há liberdade necessariamente na competição de ideias, ainda que o jogo do conflito em rede possa ser até mesmo sedutor, para alguns. O homemmáquina, vencido, considera a sua liberdade cerceada. O homem-máquina, vencedor, considera que a liberdade prevaleceu. A confusão entre ser livre e ser vencedor é um dos contrastes trazidos pela pós-modernidade.

\section{A dimensáo pública das redes sociais}

A rede social e a internet possuem uma dimensão pública e, dessa forma, é impossível náo imaginar os resultados do exercício dessa liberdade irrestrita, e aqui não é defendido que não devam existir liberdades, obviamente, mas o exercício irrestrito dessa liberdade irá levar o indivíduo, inserido no ciberespaço, a viver em um estado de natureza virtual, que eliminará a necessidade de preocupação com o outro ou com a extensão de suas açôes dentro do "espaço virtual", dessa forma, surgirá um novo tipo de se compreender conceitos antigos para o direito como a cidadania, por exemplo.

Esse individuo no ciberespaço passará a ter um espaço muito maior para ecoar seus sentimentos, as suas sensaçôes, necessidades, ira, angústia, inclusive, sobrepondo todas elas diante de outros indivíduos. As redes sociais representarão a amplificação da rede de relacionamento com o um único fim, transformar a vida individual em objeto de desejo de outros, o espetáculo das redes sociais servirá para trazer, justamente, esse capital virtual, permitido pela falta de mecanismos de organização efetiva desse espaço virtual.

Lemos e Levy irão tratar muito bem essa questão da nova dimensão da esfera pública no ciberespaço, ao prever que essa nova dinâmica social que ocorre nesse "mundo virtual" imaginário forçará uma compreensão mais expandida do mundo:

O cidadão nessa nova esfera pública não está mais obrigado a restringir o seu ponto de vista e acesso à informação ao que se inscreve ou é dito na esfera pública midiática de massa. Há possibilidades de acesso a pontos de vista de um conjunto de atores em debate ou em conflito. Mais ainda, pode-se produzir uma visão de mundo independente 
e distribuí-la livremente, sob diversos formatos. Nossa compreensão do mundo pode tornar-se necessariamente mais vasta e mais aberta ${ }^{14}$.

E as trocas ocorridas dentro dessas redes sociais, possibilitadas pelo exercício pleno de uma equivocada noção de liberdades irrestritas, irá permitir o desenvolvimento de relaçóes voláteis em torno da exposição do "eu", como uma forma de exteriorizar os desejos individuais se sobrepondo ao outro, essa sensação de plenitude será o ópio inebriante que acalantará a alma do "animal homem" no estado de natureza virtual. Se para Hobbes a forma de limitar essa realidade terrível humana seria através do contrato social, no "mundo virtual" não é possível estabelecer essa relação, talvez "O Código" 15 pudesse representar esse contrato social.

De fato, a crença de que viver a vida no ciberespaço é mais possível do que viver a vida no "mundo real" e toda a complexidade contida dentro dessa ideia, só é possível, pois a ausência da porção humana lá, fica evidente, ou seja, na rede social cada indivíduo é um personagem, um avatar, que se relaciona com diversos personagens ou avatares. As relaçóes são idealizadas, são simbólicas e a noção de que essa vida é a vida perfeita não passa de uma falsidade, que servirá de justificativa para liberdades irrestritas, mas que, também, representará um bálsamo às inquietudes da alma.

Será possível, em Nietzsche, justamente, identificar a falsidade em relação ao mundo que vivemos:

Seja qual for o ponto de vista filosófico no qual nos coloquemos, deve ser reconhecido que a falsidade do mundo em que acreditamos viver é a coisa mais verdadeira e firme que nossa visão pode apreender. Encontramos repetidamente razóes que nos fazem supor que existe na essência das coisas um princípio que o nosso pensamento pela falsidade do mundo, isto é "o espírito"- saída honrosa, seguido por todo advocatus dei consciente ou inconsciente. Quem tomar como erradamente interpretado este mundo com o espaço, tempo, forme e movimento, terá boas razóes, pelo menos, para finalmente aprender a desconfiar do próprio pensar ${ }^{16}$.

Portanto, as redes sociais permitem que os indivíduos criem suas próprias imagens idealizadas como forma de expor a intimidade, a vida, em busca de um capital virtual, dessa forma, representando uma maximização de uma individualidade perversa ao eliminar quase por completo a necessidade de empatia, aliadas à uma extensão impossível de se imaginar, que se cria em relação à ideia de espaço e dimensão do que é o espaço o público.

Cada pessoa poderá construir seu próprio mundo, sua própria realidade dentro do seu espaço individual contido na sua rede social, que terá um reflexo efetivo no mundo real com uma relação com a extensão que essa vida virtual terá de resultado em uma nova possibilidade de expansão da dimensão pública da vida vivida no mundo virtual. Qual será a concepção de liberdade individual? O homem-máquina supera a ideia de liberdade por violência positiva

14 LEMOS, André; LEVY, Pierre. O futuro da internet: em direção a uma ciberdemocracia. São Paulo: Paulus, 2010, p. 77.

15 Cf. Lessig: "Vivemos a vida no espaço real, sujeito aos efeitos do código. Nós vivemos vidas comuns, sujeitos aos efeitos do código. Vivemos vidas sociais e políticas, sujeitas aos efeitos do código. O código regula todos esses aspectos de nossas vidas, mais abrangentes ao longo do tempo do que qualquer outro regulador em nossa vida. Devemos permanecer passivos sobre essa regulação? Devemos deixar isso afetar-nos sem fazer nada em troca?". LESSIG, Lawrence. Code and other laws of cyberspace. New York: Basic Books, 1999, p. 28.

16 NIETZCHE, Friedrich W. Além do Bem e do Mal: Prelúdio de uma filosofia do futuro, trad. Armando Amado Júnior. São Paulo: WVC Editora, 2001, p. 58. 
e permite o revival da eticidade e da socialidade no compartilhamento de informaçóes e na construção de novos conhecimentos?

A gênese sociológica da sociedade da informação, conforme Tadao Umesao, é o compartilhamento por solidariedade, a partir do exercício de liberdade responsável. Superase a luta pela prevalência de ideias a qualquer custo, num sentido de cooperação mútua para desenvolvimento recíproco ${ }^{17}$.

O homem-máquina deve ser eticizado, assim como o homem do mundo real. A dimensão pública das redes sociais torna indispensável a adoção de instrumentos inibitórios da violência positiva como maneira de anular o outro.

Por isso, observa Armand Mattelart que a escola norte-americana do free flow of information, que preconiza a doutrina da liberdade absoluta do tráfego de informaçôes na rede, náo obteve o apoio que desejava da sociedade internacional, quando dos debates iniciados nos anos 1990, pelo G8, sucedidos por importantes discussóes entre os integrantes das Naçóes Unidas, culminando na elaboração da Declaração de Genebra, de 2003, sobre o sociedade da informação. Essa Cúpula Mundial discutiu a necessidade da regulação global do acesso à informação e dos conteúdos de comunicação ${ }^{18}$.

\section{Conclusáo}

O estado de natureza hobbesiano irá evidenciar o homem na sua porção mais primitiva, onde ele cede qualquer noçáo de racionalidade aos seus desejos instantâneos, suas necessidades momentâneas, renegando, de certa forma, a sua própria porçáo humana. $\mathrm{O}$ homem nesse estado é animal, um animal que anula o outro como forma de alimentar a sua sede por liberdade, por viver a máxima potência da sua vida.

A liberdade irrestrita legitimará essa forma de viver, em uma constante corrida em busca de satisfação, de prazer, de positividade, pouco importando a vida coletiva ou a consequência dos atos, já que tudo é efêmero, tudo é passageiro dentro do estado de natureza. A ideia de sociedade é substituída pela ideia de individualidade, qualquer noção de razão ou de consequência encontra óbice no desejo incansável pela liberdade, nesse sentido a liberdade humana encontra seu lado perverso.

Para isso, Hobbes irá propor uma forma de limitação dessas liberdades irrestritas, uma forma de fazer cessar esse estado de natureza, já que a consequência lógica é a própria extinção dos indivíduos, a finalização da existência. A finalidade do contrato social será, justamente, estabelecer os limites dessas liberdades e entregar a um outro ente, o Estado, a possibilidade de regular, de controlar esse indivíduo em sociedade e não mais no estado de natureza.

As redes sociais correspondem a própria vida vivida, a própria existência humana, mas "funcionam" dentro de um ambiente virtual, dentro de um campo intangível, mas que está sujeito aos efeitos das normas produzidas no "mundo real", portanto as relaçóes estão sujeitas da mesma forma ao contrato social. O Estado existe, também como ente regulador, com o império do seu poder em todas as manifestações virtuais e que produzem efeitos reais.

17 SENISE LISBOA, Roberto. Direito na sociedade da informação: a contribuição japonesa, p. 28.

18 MATTELART, Armand. História da sociedade da informaçáo, p. 162-163. 
No entanto, a possibilidade de liberdade e dificuldade de regulação da internet, quer seja por questóes sociais, quer seja por questóes técnicas como, por exemplo, o aspecto estrutural constituinte dessa própria rede mundial de computadores, representa um sério empecilho ao poder de império do Estado e a consequente imposição do contrato social, dando margem ao surgimento de uma crença baseada no exercício de liberdades irrestritas que perpassam a capacidade regulatória do Estado, por óbvio, desafiando a própria aplicaçáo do Direito.

Em um ambiente de liberdades irrestritas, surgirá a possibilidade de volta a um estado de natureza hobbesiano, só que não existente em um mundo real, onde nesse mundo o contrato social existente é externado através do poder estatal e no ordenamento jurídico, mas dentro de um ambiente virtual, onde esse contrato social é mitigado, as liberdades e suas manifestaçôes em algumas formas podem ser consideradas irrestritas.

O ciberespaço possibilitará através das redes sociais a criação do ambiente propicio a volta do homem ao seu estado primitivo de desejo de satisfação das necessidades imediatas, da eliminação da empatia, da desnecessidade do outro, esse indivíduo dentro das redes sociais irá viver dentro de um estado de natureza, um estado de natureza virtual.

Esse comportamento será pautado em uma noção de que nessas redes é possível o exercício da liberdade de expressão de forma irrestrita, assim, justificando qualquer tipo de comportamento no seu interior, já que esse espaço só possui finalidade para que ocorra essa exposição, o combustível das redes sociais é a exposição da vida, mas isso tem uma finalidade, que é a de receber em troca, pela exposição, notoriedade, autoridade social, protagonismo virtual, a capacidade de tornar exclusiva e eterna a vida exposta, vivida nessas plataformas.

Essa exposição revelará a porção mais egoísta dos indivíduos, que em busca dessa notoriedade, irá competir com outros indivíduos na corrida por likes ou compartilhamentos, será uma busca incansável pela superação do outro, dessa forma a melhor maneira de alcançar esse êxito é anulando, eliminando o outro.

Mas como fazer isso? A própria dinâmica dessas redes sociais é voltada para essa possibilidade, pois quanto mais capital virtual o indivíduo possuir, mais status possuirá, e assim como a lei da natureza e, nesse caso, no estado de natureza virtual, o mais forte prevalecerá face ao mais fraco. A exposição e o espetáculo, permitirão que o exercício dessas liberdades irrestritas sirva para eliminar qualquer possível "concorrente" ou obstáculo que impossibilite o atingimento desse objetivo.

O lobo homem no estado de natureza virtual é o animal entorpecido pela sua própria imagem idealizada, tendo sua existência garantida no exercício das liberdades irrestritas dentro das redes sociais, nesse sentido, os indivíduos consumirão a vida dos outros, mas também perderão a sua porção de vida ao ter a sua vida consumida. Esse ciclo vicioso só servirá para diminuir, cada vez mais, a humanidade que cada um possui dentro de si, formando uma coletividade de animais em um estado de natureza virtual.

\section{Referência}

ASIMOV, Isaac. Eu, Robô. São Paulo: Aleph, 2015. 
ARENDT, Hannah. A condiçáo humana; trad. Roberto Raposo, 10ª ed. Rio de Janeiro: Forense Universitária, 2005.

BARBOSA, Marco Antônio. Pós-modernidade: a identidade real ou virtual? Revista Direitos Culturais, Santo Ângelo, v.5, n.8. Jan/jun.2010.

BAUMAN, Zygmunt. A Modernidade líquida. Rio de Janeiro: Jorge Zahar, 2001.

BORDIEU, Pierre. A Distinçáo: crítica social do julgamento, 2a . ed. Porto Alegre: Zouk, 2017.

GIDDENS, Anthony. A constituiçáo da sociedade, trad. Álvaro Cabral, 3ª ed. São Paulo: Editora WMF Martins Fontes, 2009.

HAN, Byung-Chul. Topologia da violência. Petrópolis: Vozes, 2017.

HOBBES, Thomas. Leviatá, ou Matéria, Forma e Poder de um Estado Eclesiástico e Civil. Col. Os Pensadores. São Paulo: Ed. Abril Cultural, 1979.

LANIER, Jaron. Dez argumentos para você deletar agora suas redes sociais. Rio de Janeiro: Intrinseca, 2018.

LEMOS, André; LEVY, Pierre. O futuro da internet: em direção a uma ciberdemocracia. São Paulo: Paulus, 2010.

LESSIG, Lawrence. Code and other laws of cyberspace. New York: Basic Books, 1999.

MATTELART, Armand. História da sociedade da informaçáo. São Paulo: Loyola, 2002.

NIETZCHE, Friedrich W. Além do Bem e do Mal: Prelúdio de uma filosofia do futuro, trad. Armando Amado Júnior. São Paulo: WVC Editora, 2001.

SENISE LISBOA, Roberto. Direito na sociedade da informaçáo: a contribuiçáo japonesa. In: Direito na sociedade da informação IV - movimentos sociais, tecnologia e a atuação do Estado. (Coord. Roberto Senise Lisboa). Coimbra: Almedina, 2020. 